\title{
Inter-instrumental comparison for the measurement of electrolytes in patients admitted to the intensive care unit
}

This article was published in the following Dove Press journal:

International Journal of General Medicine

16 May 2017

Number of times this article has been viewed

\section{Vivek Pant' \\ Arjun Tumbapo' \\ Bipin Karki}

'Department of Biochemistry, Institute of Medicine, Tribhuvan University Teaching Hospital, ${ }^{2}$ Department of Anesthesia, Institute of Medicine, TUTH, Kathmandu, Nepal

Video abstract

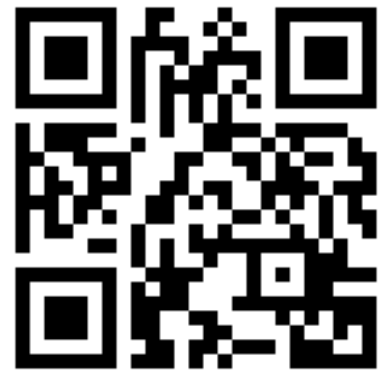

Point your SmartPhone at the code above. If you have a QR code reader the video abstract will appear. Or use: http://youtu.be/OYy6W-fXozQ
Correspondence: Vivek Pant

Department of Biochemistry, Institute of Medicine, Tribhuvan University Teaching Hospital, Maharajgunj Rd, Kathmandu 44600, Nepal

Tel +977984l48 6789

Email drvpant@gmail.com
Objective: To investigate whether benchtop auto-analyzers (AAs) and arterial blood gas (ABG) analyzers, for measuring electrolyte levels of patients admitted to intensive care units (ICU), are equal and whether they can be used interchangeably.

Materials and method: This study was conducted on 98 patients admitted to the ICU of the Institute of Medicine, Kathmandu, Nepal between 15 October and 15 December 2016. The sample for AA was collected from the peripheral vein through venipuncture, and that for ABG analyzer was collected from radial artery simultaneously. Electrolyte levels were measured with ABG analyzer in the ICU itself, and with benchtop AA in the central clinical biochemistry laboratory. Results: The mean value for sodium by AA was 144.6 (standard deviation [SD] 7.63) and by ABG analyzer 140.1 (SD 7.58), which was significant ( $p$-value $<0.001$ ). The mean value for potassium by AA was 3.6 (SD 0.52) and by ABG analyzer 3.58 (SD 0.66). The Bland-Altman analysis with the $95 \%$ limit of agreement between methods were -4.45 to $13.11 \mathrm{mmol} / \mathrm{L}$ for sodium and the mean difference was $4.3 \mathrm{mmol} / \mathrm{L}$ and -1.15 to $1.24 \mathrm{mmol} / \mathrm{L}$ for potassium and the mean difference was $0.04 \mathrm{mmol} / \mathrm{L}$. The United States Clinical Laboratory Improvement Amendments accepts a $0.5 \mathrm{mmol} / \mathrm{L}$ difference in measured potassium levels and a $4 \mathrm{mmol} / \mathrm{L}$ difference in measured sodium levels, in the gold standard measure of the standard calibration solution. The passing and Bablok regression with $95 \%$ confidence interval has an intercept of zero and slope one for both sodium and potassium, and the $95 \%$ of random difference is -6.32 to 6.32 for sodium and -0.84 to 0.84 for potassium, showing no significant deviation from linearity. Conclusion: It can be concluded that $\mathrm{AA}$ and $\mathrm{ABG}$ analyzers may be used interchangeably for measurement of potassium in the Institute of Medicine, while the same cannot be concluded for the measurement of sodium, because of the significant difference in sodium measurement by the two instruments.

Keywords: benchtop auto-analyzers (AA), arterial blood gas (ABG) analyzers, intensive care unit (ICU)

\section{Introduction}

Ion-selective electrode (ISE) is the most routinely used method for electrolyte estimation in clinical laboratories. There are two types of ISE measurements based on sample preparation. Direct ISE uses an undiluted sample to interact with ISE membrane, and the devices based on indirect ISE use preanalytical dilution. Direct ISE may use whole blood as in the case of an arterial blood gas (ABG) analyzer, or may use serum as in the case of benchtop auto-analyzers (AAs).

Studies using different devices have reported different results. It is, therefore, important to determine the concordance of electrolyte values obtained by various 
methods. Moreover, there are a lot of studies comparing the results of electrolytes in an arterial sample processed by an ABG analyzer, and serum sample processed by a benchtop AA, both of which use the direct ISE method without any need for pre-dilution of the sample. The present study was done with the objective to investigate whether the results from ABG analyzers and AAs are equal when used to assess electrolyte levels (sodium and potassium), in the Institute of Medicine (IOM), Kathmandu.

\section{Materials and method}

A cross-sectional observational study was conducted for a period of 2 months, ie, 10 October to 10 December 2016, in the Central Biochemistry Laboratory and intensive care unit (ICU) of IOM. Ethical clearance to conduct the study was obtained from the Institutional Research Board of IOM reference number 293(6-11-E $)^{2} / 073 / 074$. Oral consent was taken from patients to be part of this research. The sample from patients admitted to the ICU was included in the study. We maintained a record of electrolyte results from $\mathrm{ABG}$ analyzers and benchtop AA for those cases from whom simultaneous arterial and venous blood was drawn. The serum sample was obtained by withdrawing $3 \mathrm{~mL}$ of venous blood in a plain vacutainer through venipuncture under aseptic conditions. The arterial sample was collected in a $2 \mathrm{~mL}$ plastic syringe in a sterile environment. The syringe was flushed thoroughly with a solution of liquid heparin $(1: 10,000)$, which was removed completely before drawing the sample. Quality control was ensured by having the blood samples collected by trained staff of the ICU and analyzed on a benchtop AA located in the central laboratory, and ABG machine located in the ICU under similar environmental conditions, and calibrated using standard protocol.

ABG samples received in heparinized syringes were processed immediately for electrolytes, and the samples received in vacutainers for serum were centrifuged within 30 minutes after collection. Electrolytes were measured with a benchtop AA (Fully Automated Electrolyte Analyzer EX-D, JOKOH CO. LTD, Japan) and with an ABG analyzer (pHox Ultra, Nova Biomedical, Waltham, MA, USA). Both instruments work on the principle of direct ISE. The reference ranges for sodium and potassium were taken as $135-145 \mathrm{mmol} / \mathrm{L}$ and 3.5-5.2 $\mathrm{mmol} / \mathrm{L}$, respectively.

Statistical analysis was done using MedCalc statistics software version 17.2. Agreement between the two analyzers was assessed using the Bland-Altman approach. ${ }^{1,2}$ Limit of agreement was defined as mean bias \pm 2 standard deviation (SD). We used a mountain plot to compare different distributions between methods as a complementary plot to Bland-Altman findings. ${ }^{3}$ The mountain plot provides information about the distribution of the differences between methods. ${ }^{1}$ If two assays are unbiased with respect to each other, the mountain will be centered over zero and long tails in the plot reflect large differences between the methods. ${ }^{4}$ Passing and Bablok plot was used to estimate agreement between two methods and to check for linear model validity. ${ }^{5-7}$

\section{Results}

The mean sodium level measured by $\mathrm{ABG}$ analyzer and benchtop AA was $140.1( \pm 7.58) \mathrm{mmol} / \mathrm{L}$ and 144.6 $( \pm 7.63) \mathrm{mmol} / \mathrm{L}$, respectively, as shown in Table $1 .{ }^{1} \mathrm{~A}$ Bland-Altman comparison of $\mathrm{AA}$ and $\mathrm{ABG}$ analyzer for the sodium measurement results revealed that the limits of agreement were between -4.45 to 13.1 and the mean difference was $4.3 \mathrm{mmol} / \mathrm{L}$ (Figure 1). ${ }^{8}$ Similarly, for potassium the limit of agreement ranged from -1.15 to 1.24 and the mean difference was $0.04 \mathrm{mmol} / \mathrm{L}$. The mountain plot is shown in Figure 2 as a complementary plot to BlandAltman plot. ${ }^{1,5}$ Likewise, Passing and Bablok regression with $95 \%$ confidence interval (CI) has an intercept of zero,

Table I Comparision of statistics obtained from AA and ABG analyzer for sodium and potasssium

\begin{tabular}{lllllllllll}
\hline $\begin{array}{l}\text { Electrolytel } \\
\text { machine }\end{array}$ & Valid & Mean & $\begin{array}{l}\text { Standard error } \\
\text { of mean }\end{array}$ & Median & Mode & $\begin{array}{l}\text { Standard } \\
\text { deviation }\end{array}$ & Variance & Range & Minimum & Maximum \\
\hline Sodium & & & & & & & & & & \\
AA & 98 & 144.459 & 0.7708 & 145.000 & 143.0 & 7.6309 & 58.230 & 41.0 & 124.0 & 165.0 \\
ABG analyzer & 98 & 140.134 & 0.7658 & 139.750 & 135.5 & 7.5812 & 57.475 & 38.2 & 118.1 & 156.3 \\
Potassium & & & & & & & & & & \\
AA & 98 & 3.632 & 0.0533 & 3.550 & $3.4^{\mathrm{a}}$ & 0.5277 & 0.278 & 2.6 & 2.7 & 5.3 \\
ABG analyzer & 98 & 3.588 & 0.0675 & 3.435 & $3.4^{\mathrm{a}}$ & 0.6684 & 0.447 & 4.5 & 2.0 & 6.5 \\
\hline
\end{tabular}

Notes: aultiple modes exist. The smallest value is shown.

Abbreviations: $A A$, auto-analyzer; $A B G$, arterial blood gas. 
A

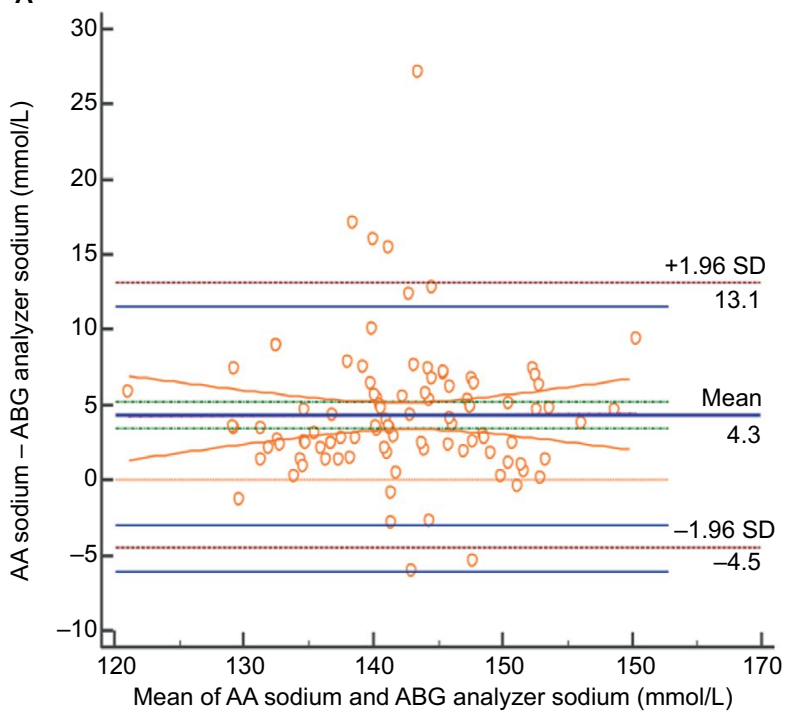

Figure I Bland-Altman plot of sodium (A) and potassium (B).

Abbreviations: $A A$, auto-analyzer; $A B G$, arterial blood gas; $S D$, standard deviation.

A

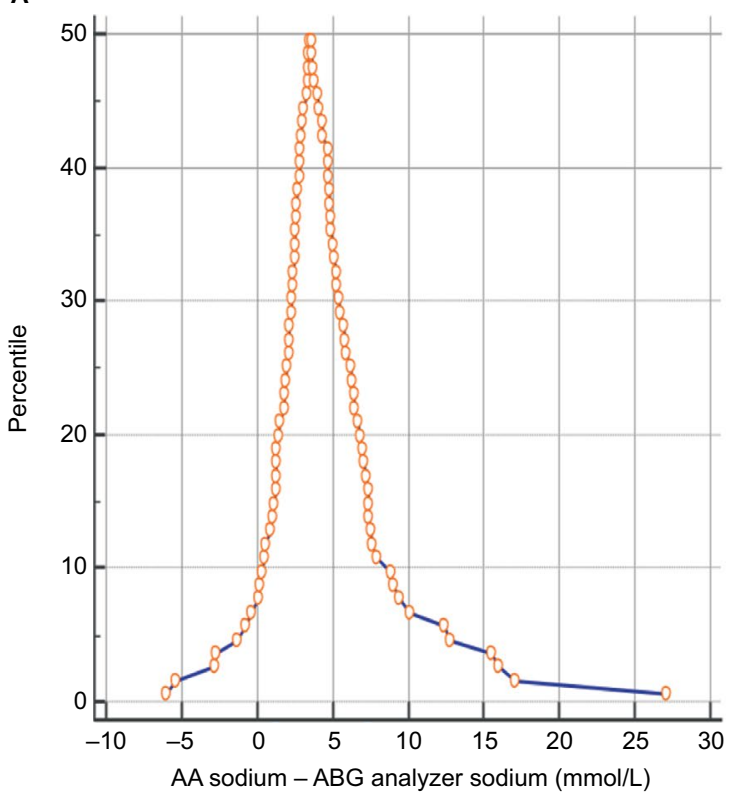

Figure 2 Mountain plot for sodium (A) and potassium (B)

Abbreviations: $A A$, auto-analyzer; $A B G$, arterial blood gas.

showing no systematic differences and slope one, showing no proportional differences in both sodium and potassium measurements by the two instruments..$^{5-7}$ The $95 \% \mathrm{CI}$ is -6.32 to 6.32 for sodium and -0.84 to 0.84 for potassium. The cumulative sum test for linearity shows a $p$-value 0.10 for sodium and 0.85 for potassium, signifying no significant deviation from linearity (Figure 3). The United States Clinical Laboratory Improvement Amendments (US CLIA)
B

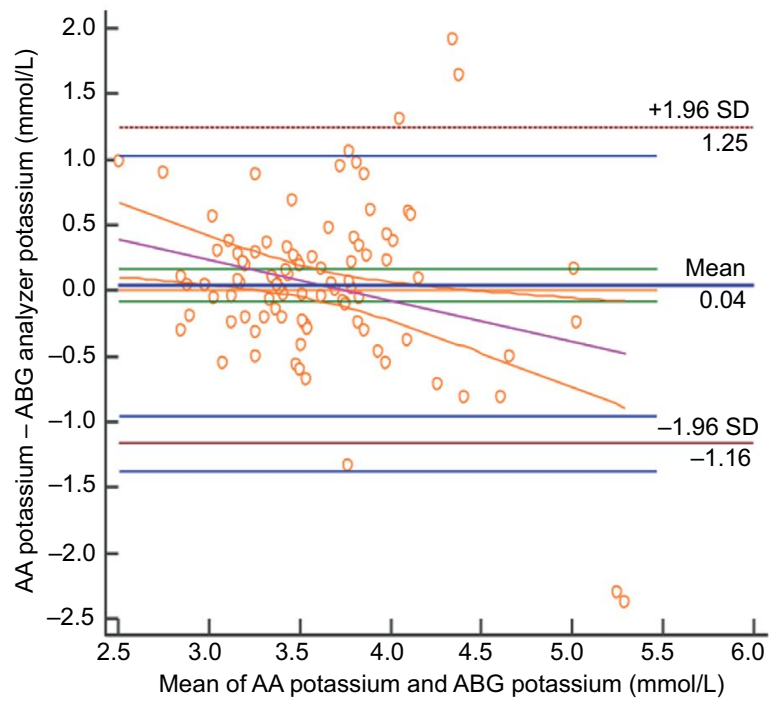

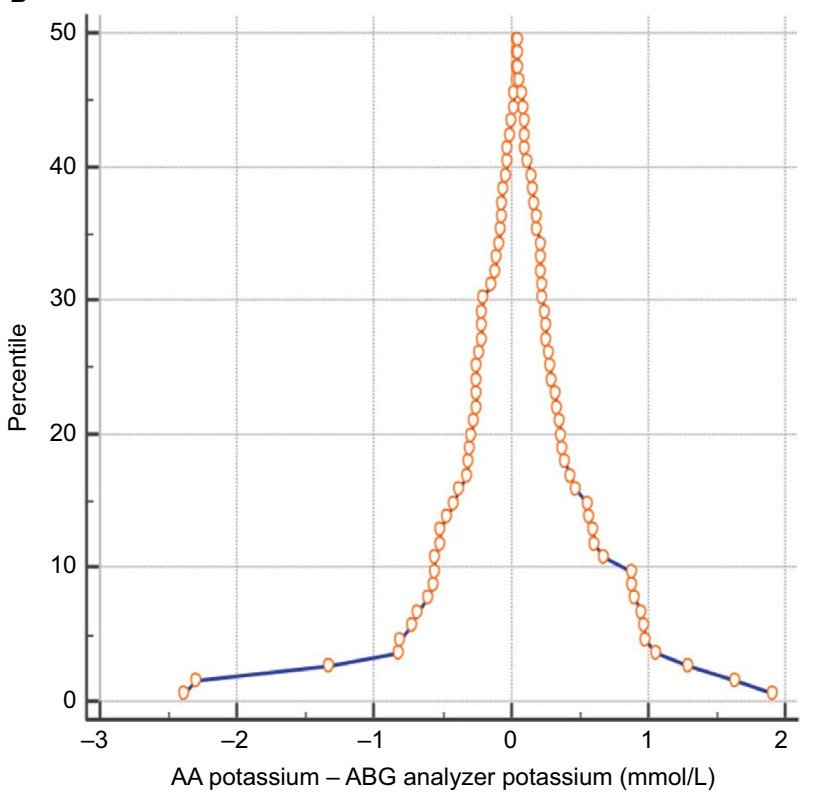

accepts a $0.5 \mathrm{mmol} / \mathrm{L}$ difference in measured potassium levels and a $4 \mathrm{mmol} / \mathrm{L}$ difference in measured sodium levels, in the gold standard measure of the standard calibration solution. In this scenario, even though the methods of measurement of the two instruments are comparable, the mean difference of sodium between AA and ABG analyzer was $4.3 \mathrm{mmol} / \mathrm{L}$, which is not within the acceptable limit for sodium as defined by the US CLIA. 
A

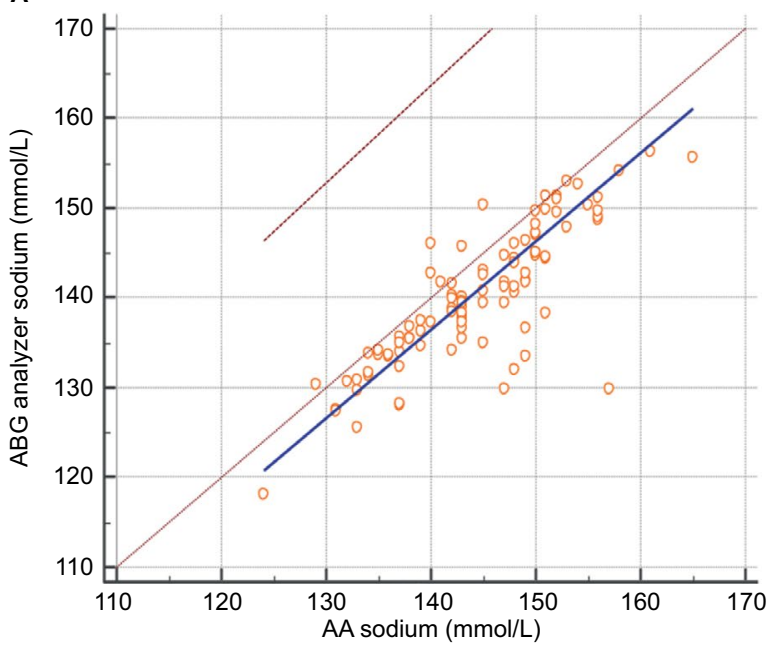

B

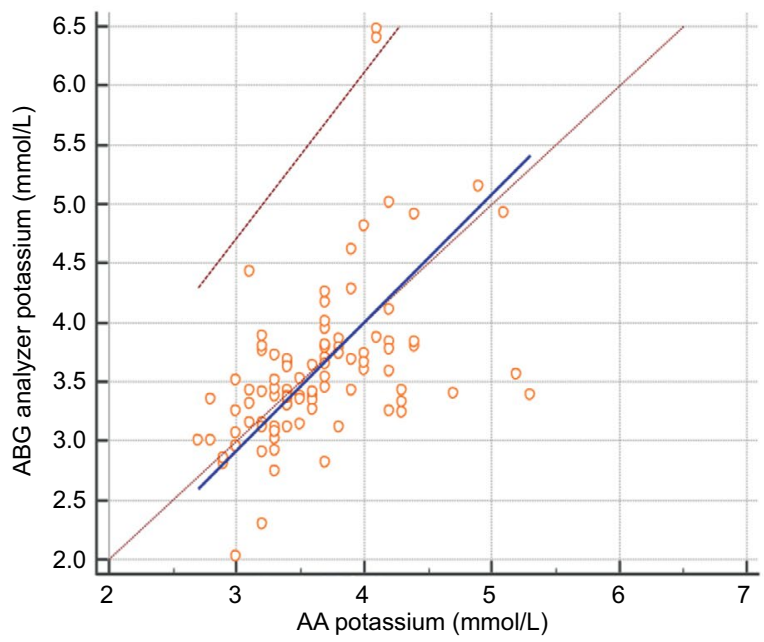

Figure 3 Passing and Bablok regression analysis of sodium (A) and potassium (B). Abbreviations: $A A$, auto-analyzer; $A B G$, arterial blood gas.

\section{Discussion}

From the dawn of civilization, human beings have been developing new technologies for the benefit of society. Similarly, automation has brought a revolution to the biochemistry analyzing process. The discovery of new techniques has provided options to choose various instruments for analyzing data of the analytes. Thus, we need to analyze variations among different methods used in hospitals for the benefit of the patient.

Electrolyte abnormalities are one of the common reversible causes of morbidity and mortality in patients admitted to the ICU. Moreover, signs and symptoms of electrolyte disorder may be nonspecific in ICU patients. The levels of electrolytes need to be monitored on a regular basis in these patients, which are ordered in $\mathrm{ABG}$ or serum sample, as per the convenience of sampling and requirement. The results of both types of measurements are used in an interchangeable manner with the assumption that they are equal. On average, 150-160 samples for electrolyte estimation are ordered every day in the biochemistry lab, and 40-50 samples are ordered every day for ABG analysis in ICU in the IOM. We included only those patients from whom simultaneous arterial and venous blood could be drawn.

Various types of instruments are available for measurement of electrolytes, and every institution should establish their own protocol for acceptance of the results obtained by these instruments. The use of different techniques is not a limitation in the present study, as we have compared results of two instruments using the direct ISE method.

The mean difference for potassium between $\mathrm{AA}$ and $\mathrm{ABG}$ was $0.04 \mathrm{mmol} / \mathrm{L}$. The magnitude of difference in our study was consistent with the literature data, as reported earlier. ${ }^{9}$ The US CLIA accepts a $0.5 \mathrm{mmol} / \mathrm{L}$ difference in measured potassium levels, and a $4 \mathrm{mmol} / \mathrm{L}$ difference in measured sodium levels, in the gold standard measure of the standard calibration solution. The value for potassium was within the acceptable limits of the US CLIA. ${ }^{10}$ Furthermore, there was a strong correlation between the results of the two instruments, concomitant with the acceptable $95 \%$ limits of agreement in the Bland-Altman analysis. The mean difference in the measurement of sodium by the two instruments is $4.3 \mathrm{mmol} / \mathrm{L}$, which is not within the acceptable limits as per the US CLIA. The use of different heparin volumes for flushing ABG sampling syringes dilute the whole blood and lower the levels of measured electrolytes in ABG testing, which could provide a meaningful explanation for lower values of electrolytes measured by the ABG machine. Since the normal range for sodium is higher than potassium, sodium values might be largely affected by dilution, giving lower values in ABG machine than AA. The study agrees with previous studies that sodium values obtained from $A B G$ machines are not reliable for making clinical decisions. ${ }^{11}$ The small sample size and use of different volumes of heparin for ABG samples, are limitations of the study.

\section{Conclusion}

It can be concluded that benchtop AAs and ABG analyzers may be used interchangeably for measurement of potassium in the IOM, while the same cannot be concluded for the measurement of sodium because of the significant difference in sodium measurements by the two instruments. 


\section{Disclosure}

The authors report no conflicts of interest in this work.

\section{References}

1. Altman DG, Bland JM. Measurement in medicine: the analysis of method comparison studies. Statistician. 1983;32:307-317.

2. Fernandez R, Fernandez G. Validating the Bland-Altman Method of Agreement. West Users SAS Softw 2009 Proc. 1986;1-17. Available from: http://www.wuss.org/proceedings09/09WUSSProceedings/ papers/pos/POS-Fernandez.pdf. Accessed January 9, 2017.

3. Krouwer JS, Monti KL. A simple, graphical method to evaluate laboratory assays. Eur J Clin Chem Clin Biochem. 1995;33(8):525-528.

4. medcalc.org [homepage on the Internet]. Software M. MedCalc. 2017. Accessed April 24, 2017.

5. Linnet K. Performance of Deming regression analysis in case of misspecified analytical error ratio in method comparison studies. Clin Chem. 1998;44(5):1024-1031.

6. Martin RF. General deming regression for estimating systematic bias and its confidence interval in method-comparison studies. Clin Chem. 2000;46(1):100-104.
7. Design E. Passing-Bablok Regression for Method Comparison:1 -12 Available from: https://ncss-wpengine.netdna-ssl.com/wp-content/ themes/ncss/pdf/Procedures/NCSS/Passing-Bablok_Regression_for_ Method_Comparison.pdf. Accessed January 9, 2017.

8. Giavarina D. Understanding Bland Altman analysis. Biochem Med (Zagreb). 2015;25(2):141-151.

9. Zhang JB, Lin J, Zhao XD. Analysis of bias in measurements of potassium, sodium and hemoglobin by an emergency department-based blood gas analyzer relative to hospital laboratory autoanalyzer results. PloS One. 2015;10(4): 0122383.

10. Ehrmeyer SS, Laessig RH, Leinweber JE, Oryall JJ. 1990 Medicare/ CLIA final rules for proficiency testing: minimum intralaboratory performance characteristics ( $\mathrm{CV}$ and bias) needed to pass. Clin Chem. 1990;36(10):1736-1740.

11. Morimatsu H, Rocktäschel J, Bellomo R, Uchino S, Goldsmith D, Gutteridge G. Comparison of point-of-care versus central laboratory measurement of electrolyte concentrations on calculations of the anion gap and the strong ion difference. Anesthesiology. 2003;98(5): 1077-1084.
International Journal of General Medicine

\section{Publish your work in this journal}

The International Journal of General Medicine is an international, peer-reviewed open-access journal that focuses on general and internal medicine, pathogenesis, epidemiology, diagnosis, monitoring and treatment protocols. The journal is characterized by the rapid reporting of reviews, original research and clinical studies across all disease areas.

\section{Dovepress}

The manuscript management system is completely online and includes a very quick and fair peer-review system, which is all easy to use. Visit http://www.dovepress.com/testimonials.php to read real quotes from published authors.

Submit your manuscript here: https://www.dovepress.com/international-journal-of-general-medicine-journal 